\title{
OS PROFISSIONAIS DE ENFERMAGEM DIANTE DO NASCIMENTO DA CRIANÇA COM MALFORMAÇÃO CONGÊNITA
}

\author{
Nursing Professionals Before of the Birth of \\ a Child with Congenital Malformation \\ Los Profesionales de Enfermería En el \\ Nacimiento de un Niño con Malformación Congénita
}

lêda Maria Ávila Vargas Dias

Rosangela da Silva Santos

\begin{abstract}
Resumo
Estudo de natureza qualitativa utilizou o Método História de Vida e teve por objeto de estudo a percepção da equipe de enfermagem de sua experiência em atuar no nascimento de uma criança portadora de malformação congênita. Os resultados permitiram a construção de três categorias temáticas: a percepção da equipe de enfermagem ao assistir o nascimento de uma criança com malformação congênita; as estratégias empregadas pela equipe de enfermagem; e os fatores que influenciam a atuação da equipe. 0 estudo evidenciou que a experiência de atuar no nascimento de criança malformada é percebida tanto como uma experiência prazerosa e gratificante quanto como uma experiência estressante e incômoda. A percepção dessa experiência é influenciada pela história de vida do indivíduo; processo de formação do profissional; tempo de atuação e suporte institucional em relação aos aspectos técnicos, científicos e emocionais.
\end{abstract}

Palavras-chave: Anormalidades. Saúde da Criança. Enfermagem.

\begin{abstract}
Study of qualitative nature that used the History of Life Method and had as study subject the perception of the nursing staff about the experience acting in a child's birth with congenital malformation. The result allowed the construction of three thematic categories: the perception of the nursing staff when attending a child's birth with congenital malformation; the strategies used by the nursing team; and the factors that infuse on the performance of the team. The study evidenced that the experience of acting in malformed child's birth is noticed as much a pleased and gratifying experience, as a stressful and uncomfor table experience. The perception of that experience is influenced by the history of the individual's life; process of the professional's formation; time of performance and institutional support, concerning to the relation to the technical aspects, scientific and emotional ones.
\end{abstract}

\section{Resumen}

Estudio de naturaleza cualitativa que utilizó el Método Historia de Vida y tuvo por objeto de estudio la percepción del equipo de enfermería a través de la experiencia en actuar al nacimiento de un niño portador de malformación congénita. Los resultados permitieron la construcción de tres categorías temáticas: La percepción del equipo de enfermería al asistir el nacimiento de un niño con malformación congénita; Las estrategias empleadas por el equipo de enfermería; y los factores que influencian la actuación del equipo. El estudio evidenció que la experiencia de actuar en el nacimiento de un niño malformado es percibida tanto como una experiencia que da placer y que gratifica, así como una experiencia estresante e incómoda. La percepción de esa experiencia es influenciada por la historia de vida del individuo; proceso de formación del profesional; tiempo de actuación y soporte institucional en relación a los aspectos técnicos, científicos y emocionales.
Keywords:

Abnormalities. CHild Health. Nursing.
Palabras clave:

Anormalias. Salud del Niño. Enfermería. 


\section{INTRODUÇÃO}

A malformação congênita existe desde os tempos mais remotos, havendo inúmeros tipos e gravidades variáveis. Algumas quase não causam problemas ao portador; outras são totalmente incompatíveis com a vida e contribuem consideravelmente para a morbimortalidade infantil.

As malformações podem ser de origem genética, como as anomalias cromossômicas ou de genes mutantes, ou não genética, cuja causa é, muitas vezes, desconhecida, embora existam fatores inter-relacionados, como infecções perinatais, idade materna, uso de drogas e irradiação durante a gravidez.

As gestações planejadas são as de menor risco para defeitos congênitos, por isso, a importância do acompanhamento gestacional por profissionais de saúde. 0 pré-natal efetivo é uma importante medida preventiva, pois permite a elaboração de um histórico de saúde da mãe e da criança, podendo indicar uma gravidez de risco.

A habilidade dos profissionais em conduzir essa situação vai ter profundo impacto na assistência prestada. Em muitos casos, é no nascimento que a família é informada da malformação, o que torna este momento decisivo. Por isso, acredita-se que o nascimento de uma criança malformada é uma situação conflitante não só para os pais e familiares, mas também para a equipe de saúde que assiste este nascimento.

Dentro deste contexto, a presente investigação teve como objetivo de estudo analisar a percepção que a equipe de enfermagem tem de sua experiência profissional diante do nascimento de uma criança com malformação congênita; descrever de que forma o profissional de enfermagem reage diante do nascimento de uma criança nesta circunstância e discutir as estratégias utilizadas pelos profissionais de enfermagem no enfrentamento desta conjuntura.

Acredita-se que este estudo seja relevante para a assistência, o ensino e a pesquisa, porque oferece subsídios para melhorar a qualidade da assistência de enfermagem prestada no nascimento de uma criança com malformação congênita.

\section{REFERENCIAL TEÓRICO}

A Organização Pan-Americana da Saúde ${ }^{1}$ (OPAS) conceitua malformação congênita como toda anomalia funcional ou estrutural do desenvolvimento do feto, devido a fatores originados antes do nascimento, sejam estes genéticos, ambientais ou desconhecidos. Mesmo quando o defeito não é aparente e somente se manifeste clinicamente mais tarde, é considerado uma malformação congênita.

Vários fatores influenciam a aceitação de uma criança malformada pela família. Pelchat et al. ${ }^{2}$ relacionam os principais fatores agrupados em três grandes categorias, a saber: preparação dos pais durante a gravidez, fatores sociais e culturais e atitudes da equipe de profissionais que assiste esse nascimento. As autoras referem que a preparação da mãe durante a gestação permite que ela se prepare, tanto física quanto psicologicamente, para a chegada de sua criança. Durante esse período, a mãe visualiza a imagem de sua criança, e essa imagem é composta das representações de seus preferidos, como: marido, mãe, pai, irmão, irmã. Este processo antecipatório de arranjos e adaptação faz parte da preparação à maternidade, mas é interrompido bruscamente pelo nascimento da criança malformada. Trabalhar de forma adequada e precoce essa possibilidade diminui o impacto e a frustração da mãe no momento do nascimento.

No que diz respeito à atuação do profissional de saúde, Pelchat et al. ${ }^{3}$ destacam a sua relevância, uma vez que esta poderá desencadear reações negativas ou positivas nos pais. Para uma intervenção terapêutica, as autoras recomendam que a enfermeira se posicione como instrumento facilitador do processo vivenciado pelos pais, assegurando-lhes que tem tempo e está interessada em ouvir, encorajando os pais a falarem a respeito da malformação, compartilhando com eles seus próprios sentimentos de angústia ante o processo de luto pela 'morte' do filho idealizado, buscando compreender esse processo e, principalmente, reconhecendo as próprias reações diante da situação.

Ao discutir a relação estabelecida entre os profissionais e as crianças com malformação congênita, é importante ressaltar duas questões apontadas por Glat ${ }^{4}$ : a primeira se refere à relação de poder estabelecida entre a criança com malformação e 0 profissional que a atende; a segunda diz respeito ao que 0 mote apud Glat ${ }^{4}$ chama de processo de fabricação e manutenção da deficiência, que está estreitamente ligado aos mecanismos conceituais e operacionais de legitimização do estigma. Esse processo é a maneira de a sociedade garantir a coesão, mantendo o desvio inevitável, em nível controlável. Os profissionais que atendem as crianças com malformação congênita, apesar do desejo genuíno de ajudá-las, sofrem das mesmas representações estereotipadas que o resto da população.

Santos ${ }^{5}$ a partir dos resultados obtidos em tese de doutorado infere que 0 atendimento recebido pelas mães de crianças com malformação não tem atendido às expectativas maternas, trazendo conseqüências drásticas para a criança. Segundo os resultados apontados pela autora, essas mães ressentem-se da falta de orientação, de informação correta e de apoio profissional. Parafraseando Santos ${ }^{5}$, a comunicação do diagnóstico deve ser feita de maneira simples. Como a mãe se encontra sob forte comoção, muito do que for falado acaba não sendo totalmente assimilado por ela, independente do seu nível de esclarecimento. 0 fato de ser esclarecida ou até de ter tido experiência prévia com a deficiência, profissionalmente ou não, não impede nem facilita que o choque ocorra ou que ela aceite a deficiência. Ressalta que a notícia do diagnóstico pode ser comunicada por qualquer integrante da equipe de saúde, desde de que este esteja devidamente preparado. 0 importante é que não haja postergação ou omissão da informação.

No período do nascimento e da infância, tanto a criança malformada como os pais necessitam de ajuda. Souza e Carvalho $0^{6}$ destacam a grande dificuldade em realizá-la. Para as autoras, a desinformação e desorientação dos familiares em relação ao cuidado com o filho malformado repercutem de forma decisiva no desenvolvimento da criança, na sua integração e na reestruturação do sistema familiar. As orientações são importantes e devem ser transmitidas pelos 
profissionais tão logo possível, pois a estimulação precoce favorece 0 desenvolvimento da criança malformada. Sendo assim, compete ao profissional o papel de conscientizar e capacitar as pessoas a conhecer e refletir sobre a realidade, auxiliando-as a transformar ou redimensionar suas práticas, visando melhorar a qualidade de suas vidas.

\section{REFERENCIAL METODOLÓGICO}

Considerando a forma interpretativa com que se tratou 0 objeto de estudo, escolheu-se a abordagem metodológica qualitativa, por acreditar que esta fosse a mais apropriada para conduzir a presente investigação. A pesquisa qualitativa, também chamada de naturalística, de um modo geral, enfatiza a importância de conhecer, entender e interpretar a natureza das situações e eventos quer sejam eles passados ou presentes?.

Dentro da abordagem qualitativa, elegeu-se o Método História de Vida como método de estudo da presente investigação. Também denominado Método Biográfico, é uma situação de intervenção social, de comunicação, onde se defrontam o pesquisador, com um projeto definido, e 0 pesquisado, que, aceitando a proposta, faz um relato de sua existência em que está contida uma mensagem destinada ao seu interlocutor. Segundo Brioschi e Trigo ${ }^{8}$, o método se constitui numa narrativa, cabendo ao narrador dar uma interpretação pessoal aos fatos de sua própria vida.

No presente estudo, as participantes, após terem assinado o termo de consentimento livre e esclarecido, abordaram o tema de forma livre, com o mínimo de interferência, pelo tempo que acharam conveniente. Os depoimentos foram gravados em fitas magnéticas com aquiescência das depoentes e garantia de sigilo e anonimato, respeitando as diretrizes e normas regulamentadoras de pesquisa envolvendo seres humanos, previstas na Resolução 196/96 do Conselho Nacional de Saúde. Ressalta-se que o estudo obteve a aprovação do Comitê de Ética em Pesquisa (CEP) do Instituto Fernandes Figueira, parecer $n^{0} 213 / 02$ e do CEP do Hospital Universitário Pedro Ernesto, parecer 789/HUPE.

Seguindo a recomendação de Bertaux 9 , os registros dos relatos foram transcritos imediatamente após as entrevistas, o que permitiu à pesquisadora organizar as idéias em relação ao questionamento e ao ponto de saturação. Assim como é proposto no Método História de Vida, por Daniel Bertaux, foram realizadas, concomitantemente à coleta de depoimentos, a transcrição e análise das entrevistas.

$\mathrm{Na}$ busca de atingir os significados manifestos e latentes no material, recorreu-se à Análise Temática, também chamada Análise Categorial. De acordo com Rodrigues e Leopardi ${ }^{10}$, este tipo de análise comporta um feixe de relações que podem ser graficamente apresentadas através de uma palavra, uma frase ou um resumo. Funciona pelo desmembramento do texto em unidades, em categorias, segundo reagrupamentos analógicos.

Foram convidadas para participar do estudo as integrantes da equipe de enfermagem (enfermeiras, técnicas e auxiliares de enfermagem) que prestam assistência de enfermagem no período perinatal e pós-natal imediato de crianças com malformação congênita, de três maternidades públicas da cidade do Rio de Janeiro. Como critério de inclusão das participantes no estudo, foi estabelecida a necessidade de a profissional atuar em sala de parto ou alojamento conjunto; ter presenciado o nascimento de alguma criança malformada, independentemente do tempo de atuação no serviço ou na unidade; e aceitar participar do estudo, voluntariamente.

Desta forma, obteve-se um total de 30 participantes, sendo dezesseis enfermeiras, quatro técnicas de enfermagem e dez auxiliares de enfermagem. No processo de coleta de dados, soube-se que, dentre as auxiliares e técnicas de enfermagem, cinco estavam em processo de formação acadêmica no Curso de Graduação em Enfermagem, e que uma das participantes passou pela vivência de ter concebido uma criança com malformação congênita, incompatível com a vida.

\section{APRESENTAÇÃO E DISCUSSÃO DOS RESULTADOS}

A discussão e análise dos depoimentos foram construídas a partir da transcrição, leitura, codificação, desdobramento, agrupamento e síntese dos depoimentos, resultando nas três categorias seguintes:

\section{I - A percepção da equipe de enfermagem ao assistir o nascimento de uma criança com malformação congênita.}

Esta categoria aborda a percepção que as participantes têm de sua experiência em assistir o nascimento de uma criança malformada, as dificuldades e os sentimentos que permeiam essa experiência. As participantes descreveram diversos casos de nascimento de crianças malformadas que assistiram ao longo de suas atuações profissionais. Inicialmente, falavam com muita naturalidade, contavam detalhes das características estéticas do recém-nascido malformado, mas à medida que a conversa evoluía, tornavam-se visivelmente mais reflexivas, chegando a mencionar o quanto o nascimento de uma criança malformada gera desconforto entre os profissionais de enfermagem e como é difíil enfrentar esta situação. 0 depoimento ilustra essa percepção:

(...) A gente se sente muito mal quando nasce uma criança malformada, é difícil e vou ser sincera eu não gosto, acho muito ruim, é sempre muito chocante, a gente sofre muito quando a gente vê (...). (Colias)

A partir da leitura do depoimento, podemos aludir que 0 nascimento de uma criança portadora de malformação congênita é uma situação difícil e estressante para a equipe de enfermagem. As depoentes, ao descreverem o desconforto em lidar profissionalmente com o diferente e com os limites da vida, referiram que a experiência resulta em sofrimento. 0 depoimento abaixo evidencia o sofrimento da equipe de enfermagem ao assistir o nascimento de uma criança com malformação congênita:

(...) A gente procura dar um bom atendimento. Hoje tem cirurgia para isso, cirurgia para aquilo, mas tem horas que desanima, o sofrimento é tanto que tem momentos que a gente desanima mesmo. Élegal quando você acompanha uma ameaça de parto prematuro, 
fica no berçário, como a gente fala, aquecendo na incubadora até ter peso, mas depois vai embora e tudo bem, mas é bem diferente a hora que vê um malformado, se não sobreviver é triste e se sobreviver é triste também (...). (Eurema)

Diante do depoimento, fica evidenciado que, por ocasião do nascimento de uma criança malformada, os profissionais experimentam um certo grau de estresse que resulta em sofrimento. Uma das possíveis razões que levam a esse sofrimento está relacionada ao fato de que, conforme Santos ${ }^{5}$, a criança malformada remete o ser humano à mais profunda de suas raízes, que, de alguma forma, procuramos sufocar e fazemos questão de não ver. Devido a isso, nesta situação, os profissionais têm dificuldade de trabalhar com seus próprios sentimentos, reagindo com frustração e ressentimento diante de uma situação que lhes causa impotência.

Finalizando a análise da categoria denominada "A percepção da equipe de enfermagem ao assistir o nascimento de uma criança com malformação congênita", cabe ressaltar a relevância desses dados, que possibilitaram evidenciar o quanto esta é uma situação estressante para a equipe de enfermagem, pela frustração que lhe é inerente.

\section{II - As estratégias empregadas pela equipe de enfermagem ao assistir o nascimento de uma criança malformada.}

Esta categoria trata das reações desencadeadas pela experiência de atuar profissionalmente ante a malformação congênita e das estratégias utilizadas pelas participantes no enfrentamento dessa situação.

Os depoimentos evidenciam que várias reações emergem dessa experiência, tais como: empatia, busca pela espiritualidade e sublimação da situação, isolamento e banalização. Além dessas reações, outras estratégias defensivas foram mencionadas pelas participantes: procurar esquecer a qualquer custo o sofrimento cotidiano, procurar manter a vida social separada das situações do mundo do trabalho e vivenciar crises manifestadas através de doenças, tornando o corpo uma válvula de escape.

Observou-se que as participantes reagem de maneira distinta diante do nascimento de uma criança com malformação congênita. A estratégia defensiva predominante foi a empatia, que é o esforço realizado para reconhecer e compreender os sentimentos e atitudes do outro, assim como as circunstâncias que os afetam num determinado momento, ou seja, é o exercício de se colocar no lugar do outro. Segundo Haddad ${ }^{11}$, a empatia nasce da autoconsciência: quanto mais abertos formos às nossas próprias emoções, mais capazes seremos de ler os sentimentos dos outros. 0 depoimento ilustra essa reação:

Aqui tem muita mulher trabalhando, a maioria são mulheres e mulheres jovens, que estão em plena fertilidade e com certeza vão engravidar e aí vem esse tormento, porque, além da profissional, tem uma mulher. Você conviver com essas situações é complicado porque, querendo ou não, você reporta para você essa situação de gerar uma criança assim (...). (Adelpha)
Quase na mesma freqüência da empatia, as participantes mencionaram a busca pela religião. A religiosidade foi fortemente pontuada tanto pelas participantes como, segundo os depoimentos, pelos familiares das crianças que apresentam malformação congênita. Deve-se ratificar essa busca pela espiritualidade da barganha, definida por Kubler-Ross ${ }^{12}$ como mecanismo psicológico que busca retardar o inevitável, envolvendo um processo de negociação, geralmente com Deus ou com algum poder maior. No caso, as participantes não chegam a propor uma troca, ou seja, não fazem barganha com ninguém, nem mesmo com Deus; apenas buscam neste Ser Supremo um confor to para superar as adversidades surgidas em sua prática profissional. 0 depoimento abaixo ilustra esta busca pela religiosidade:

(...) Eu acredito muito em Deus, eu faço minhas orações, sempre rezo muito por isso, rezo para que Ele tire essa impressão da minha cabeça, que não deixe eu me influenciar por isso, para eu não ficar pensando (...). (Lysimnia)

Diante dos depoimentos, pode-se aludir que a fé constitui uma fonte de conforto para as participantes, favorecendo o aparecimento da estratégia defensiva de sublimação.

Uma outra estratégia defensiva observada em nosso estudo foi o afastamento, também chamado de isolamento. Segundo Gauderer $^{13}$, o enfrentamento de uma situação difícil é muito desgastante, e como tudo o que é penoso precisa ser eliminado, o profissional desenvolve um sentimento de rejeição; mas como sabe que sentimentos de raiva, rejeição e agressão vão de encontro aos preceitos preconizados pela profissão, passa a se sentir culpado. Esse sentimento, em geral, é inconsciente e se camufla em inúmeras justificativas. Um dos mecanismos utilizados para trabalhar com a situação causadora de sofrimento é promover o afastamento. Desta forma, o profissional se isola, não participa, não compartilha, não se envolve e, conseqüentemente, não sofre, conforme está expresso no depoimento a seguir:

(...) mas depois ela ficou chorosa, e eu saí até porque eu acho que eu não estava preparada, acho que eu não queria chorar junto com ela, independente de ter muito trabalho, porque às vezes você faz questão de ficar quase que distante (...). (Martia)

0 distanciamento é mencionado como uma tática para evitar o envolvimento e, conseqüentemente, o sofrimento. 0 emprego desse recurso, como forma de aliviar o desconforto sentido durante o trabalho, transmite a impressão de insensibilidade, podendo até parecer uma indiferença, o que pode ser deletério, pois que isso interfere sobremaneira nas relações estabelecidas no ambiente de trabalho. Acredita-se que a utilização dessa estratégia é empregada no sentido de autoproteção das participantes, embora este não seja o meio mais apropriado para estabelecer possibilidades de resolução dos problemas iminentes.

A banalização, outra estratégia evidenciada neste estudo, é conceituada por Beck ${ }^{14}$ como um modo de enfrentamento de 
situações importantes que provocam sofrimento e são encaradas como comuns e inerentes ao contexto em que 0 trabalhador vive. Pode-se ainda entender a banalização como um processo de simplificação dos acontecimentos, como se os eventos passassem a ser apenas mais um. É como fazer de conta que nada está acontecendo, ou como se os acontecimentos fossem esperados e não requeressem decisões.

Além das estratégias defensivas supracitadas, outras foram mencionadas pelas participantes para serem feitas diante do sofrimento, algumas delas consideradas positivas, outras nem tanto. Dentre estas últimas, destacam-se: Procurar esquecer a qualquer custo o sofrimento cotidiano, o que se considera inapropriado, porque em qualquer situação o custo deve ser sempre avaliado e, sensatamente, a relação custo-benefício é uma constante. Anular as emoções: isso pode ser uma estratégia pouco eficaz porque o beneficio, isto é, se conseguido, pode ser temporário, revertendo-se, posteriormente, em mais sofrimento.

Finalizando a categoria denominada "As estratégias empregadas pela equipe de enfermagem ao assistir 0 nascimento de uma criança malformada", ressalta-se que a relevância da equipe permite traçar uma intervenção apropriada para o aprimoramento da mesma.

III - Os fatores que influenciam a atuação da equipe de enfermagem em assistir o nascimento de uma criança portadora de malformação

Essa categoria apresenta os fatores que exercem influência na atuação da equipe de enfermagem, como: história de vida do sujeito, tempo de experiência, processo de formação acadêmica e suportes que a experiência demanda. Vários fatores são suscetíveis de influenciar a forma como o profissional interpreta essa situação, o que tem repercussão direta na sua postura. Entre estes fatores, foram identificados nos depoimentos da equipe de enfermagem: a história de vida do sujeito, o tempo de experiência, o processo de formação acadêmica e os suportes que a experiência demanda. Esses fatores consistiram-se em subcategorias, descrita a seguir:

A influência da história de vida das depoentes na experiência de assistir o nascimento da criança portadora de malformação:

Nossa história de vida é construída ao longo do tempo e assinalada pelas lembranças e impressões significativas de nossa existência. A relação afetiva estabelecida com a figura materna, no início da vida, constitui-se em uma das mais importantes significações do indivíduo. Segundo Bowlby ${ }^{15}$, o desabrochar da personalidade e da consciência só pode se dar satisfatoriamente se as primeiras relações humanas forem constantes e satisfatórias.

De acordo com os depoimentos, a frustração da mãe ao ver que seu filho é malformado, completamente diferente do idealizado, associada à preocupação em saber como vai ser a vida deste novo ser, dificulta a aceitação dessa criança e estabelece um processo relacional permeado por angústia e tristeza. A equipe de enfermagem compartilha com os familiares essa vivência e, ao fazê-lo, defronta-se com os conflitos estabelecidos a partir de sua própria história de vida. Dejours ${ }^{16}$ refere que, como a percepção do sofrimento alheio provoca um processo afetivo, perceber o sofrimento alheio resulta numa experiência sensível a partir das quais se associam pensamentos, cujo conteúdo depende da história particular do sujeito que percebe. A maioria dos profissionais de enfermagem mostrou-se sensibilizada pela fragilidade em que os pais se encontravam ao vivenciarem o nascimento de uma criança malformada. Reconheceram que o próprio encaminhamento para um hospital que atende gestações de alto risco já era causador de angústia e apreensão. $E$, de modo geral, mostraram-se solidárias e desejosas de confortar a mãe que teve um filho malformado. No entanto, algumas profissionais mostraram-se mais sensibilizadas do que outras; dentre esse grupo, algumas pessoas tinham uma vivência social, familiar, ou até mesmo particular, com malformação congênita, configurando-se essa experiência prévia um aspecto de forte repercussão na atuação profissional.

A influência do tempo de atuação na experiência de assistir o nascimento da criança portadora de malformação:

Se a experiência anterior com malformação congênita é um aspecto de forte repercussão na atuação profissional, conseqüentemente, o tempo de experiência vai ser um fator determinante. Quanto a isto, os depoimentos evidenciaram que esta é uma questão divergente, pois enquanto algumas participantes referiram que, com o passar do tempo, vão se habituando a esta situação, na medida em que as vivenciam constantemente, outras dizem não se acostumarem nunca, sendo para elas sempre um impacto vivenciar tal fato, conforme ilustra o depoimento abaixo:

(...) Eu já estou acostumada, mas no início, quando eu comecei a trabalhar aqui eu dizia: caramba! Como é que eu vou cuidar dessa criança? Porque tem umas malformações gritantes, realmente o bebê parece um monstrinho, mas isso foi muito na fase inicial, depois você se acostuma (...). (Lycorea)

Como se percebe no depoimento, parece haver uma habituação das participantes a tal situação. Contudo, concebese a idéia de que esta habituação esteja relacionada com os mecanismos de defesa dos quais o profissional lança mão no enfrentamento de uma situação de sofrimento, pois, ao refletirem sobre o cuidado prestado à unidade mãe e filho, nos casos de malformação congênita, caracterizam-no como complexo, requerendo conhecimento técnico e expressão afetiva, com isso estabelecendo uma estreita relação entre o ser cuidado e o ser cuidador, mesmo quando se deseja que esse envolvimento não aconteça. Mas como o cuidado demanda uma aproximação muito estreita, ela se torna inevitável. Por conta disso, o profissional procura se resguardar desenvolvendo estratégias defensivas pessoais, conforme foi visto na categoria em questão.

A influência do processo de formação profissional na experiência de assistir o nascimento da criança portadora de malformação:

Outro fator que exerce influência na experiência de assistir o nascimento de uma criança malformada, segundo os 
depoimentos, é o processo de formação acadêmica do profissional. No que se refere a este processo, a quase totalidade das participantes referiram que percebem uma lacuna em suas formações acadêmicas em relação à malformação congênita, que pode ser confirmada no depoimento que se segue:

\section{(...) Eu vi muito pouco de malformação congênita na} faculdade e quando você chega para assumir o cargo daí que você vai ver o que realmente é, porque quando eu fiz materno-infantil eu não me lembro de terem abordado nada disso. A gente aprende no dia-a-dia. Ah! e como a gente aprende! Tem que aprender porque, se não, como os profissionais da saúde iriam sobreviver? (...). (Cytheritis)

Pelchat e Lefèbvre ${ }^{17}$ referem que a maioria dos profissionais ainda não está preparada para este evento. Com isso, acabam transmitindo para os pais seus próprios sentimentos de choque, fracasso e rejeição, além de desenvolverem sentimentos de culpa e impotência, que resultam em sofrimento diante das muitas dificuldades do seu cotidiano.

A própria experiência da pesquisadora confirma esses achados, pois ao cursar a graduação em Enfermagem não se deparou com a discussão desse tema no processo formal de ensino. A aproximação de forma sistemática ao tema se deu como bolsista do Programa de Iniciação Científica, participante de uma pesquisa, o que não é uma experiência prevista para todo e qualquer aluno da graduação, fato suficiente para despertar as inquietações que motivaram o percurso profissional da pesquisadora. No próprio Curso de Especialização em Enfermagem Pediatria e Neonatal, realizado posteriormente, este tema não foi objeto de uma abordagem específica, e as discussões a respeito surgiam no decorrer das aulas, esporadicamente.

De acordo com Popim ${ }^{18}$, há um hiato na formação dos profissionais de saúde no que se refere ao preparo destes para lidarem com situações críticas, como nos casos de morte e de malformação. Há uma tendência em falar mais sobre a vida, às vezes até negando a iminência da morte, posição que pode inviabilizar uma correta atuação profissional.

Por fim, cabe destacar que, apesar de a literatura mostrar uma ascensão progressiva deste tema no cenário acadêmico, ainda é relativamente ínfima, tendo em vista o corolário suscitado pelo nascimento de uma criança malformada, demandando, desta forma, a contínua conquista de novos espaços de reflexão.

Os suportes que a situação demanda e a influência desses na experiência de assistir o nascimento da criança portadora de malformação:

0 despreparo acadêmico do profissional para atuar especificamente nos casos de malformação congênita exige um aprimoramento profissional e pessoal para que ele possa fazer frente a tal situação. Neste contexto, são abordadas as questões referentes aos suportes que essa situação demanda e a influência desses na experiência de assistir o nascimento da criança portadora de malformação congênita.

0 primeiro suporte refere-se aos cursos de aprimoramento. As profissionais da equipe de enfermagem entrevistadas relataram perceber a fragilidade e a especificidade do cuidado a ser prestado nos casos de nascimento de uma criança portadora de malformação congênita, experiência tida como de grande complexidade e de muita responsabilidade, que demanda constante aprimoramento e muita sensibilidade nas ações de cuidar.

0 nascimento de uma criança malformada constitui-se numa experiência que, sem dúvida, torna mais difícil a vida dos pais e até mesmo o desempenho dos profissionais. Por conta disso, esta experiência pode resultar em uma ocasião de aprendizagem para todos envolvidos. 0 contínuo aprimoramento dos profissionais é fundamental ao seu desempenho e tem repercussões significativas na assistência prestada, pois aquele que obtém a devida qualificação, além de se apresentar mais seguro, é mais eficiente em sua atuação.

Para as participantes do estudo, quando se pensa em qualidade do cuidado especializado, o suporte emocional dos profissionais se constitui num requisito indispensável, pois a efetiva preparação para tal situação demanda um preparo que vai além do técnicocientífico. Ou seja, o preparo do profissional está além dos livros; não basta que ele esteja preparado cientificamente.

Em síntese, esta categoria evidenciou os fatores que influenciam a experiência de assistir o nascimento da criança portadora de malformação congênita, considerando que as participantes das três instituições, indistintamente, reconheceram essa experiência como especial, além de exigir constante aprimoramento técnico-científico e emocional.

\section{CONSIDERAÇÕES FINAIS}

A equipe de enfermagem, ao assistir o nascimento da criança malformada, percebe sua experiência como estressante, incômoda e desconfortável, permeada por dificuldades, sendo a principal delas mostrar a criança ao pai, aos familiares e, em especial, à mãe. Surgem sentimentos de angústia, raiva, repulsão e frustração, que levam ao sofrimento.

Tal experiência, ao mesmo tempo, é vista como prazerosa e gratificante, por propiciar o desenvolvimento pessoal e profissional, despertando, inclusive, sentimentos de orgulho e satisfação por permitir a utilização de tecnologia de ponta e a oportunidade de trabalhar com o diferente.

Essa variação de sentimento entre perceber a experiência como frustrante ou prazerosa depende da singularidade do sujeito. Enquanto algumas pessoas vão achar sofrimento em tudo, até como estratégia de valorização do seu trabalho, pessoas vão usar a criatividade e buscar formas de atenuar este sofrimento. Ambas as posturas terão reflexos na saúde do indivíduo, deteriorando-a e causando ou propiciando condições que resultam na impossibilidade de mantê-la.

Neste último caso, faz-se necessário que o profissional apresente maturidade e sensibilidade para tomar consciência da própria singularidade, o que se constitui num desafio para os componentes da equipe de enfermagem, pois demanda a busca por melhores condições de trabalho que permitam um efetivo aprimoramento profissional e pessoal, atendendo as necessidades do ser que cuida, mas que também precisa ser cuidado. A Enfermagem desempenha importante papel junto aos pais de crianças malformadas, em especial na orientação dos cuidados físicos, incentivando-os no sentido de que se 
responsabilizem pelo cuidado da criança, como um preparo para o retorno ao lar, quando esses cuidados deverão continuar; e também na identificação de desvios de comportamento dos pais que possam levá-los a negligenciar ou superproteger a criança, situação que precisaria de encaminhamento especial. Mas para isso, torna-se necessário que a Enfermagem compreenda o seu papel diante desse nascimento.

Indubitavelmente, cuidar da família de uma criança malformada é tarefa de grande complexidade, por isso a prática requer um cuidado transdisciplinar, que traz como resultado uma riqueza de experiências e uma assistência efetiva a essa clientela. A família deve ser trabalhada como um todo, incluindo avós, outros filhos do casal, normais ou não, e outros membros julgados importantes, para que se consiga êxito no desenvolvimento e na integração da criança malformada. Temos que convir que cuidar de uma criança malformada é tarefa árdua, que adquire importância significativa na medida em que a família deseja, efetivamente, tornar-se responsável pelo cuidado. Sendo assim, a interação entre profissionais e familiares deve ser permeada por sentimentos de partilha.

\section{Referências}

1. Organización Panamericana de Salude - OPS. Salud materno infantil y atención primária en las Américas. Washington, DC(USA); 1994.

2. Pechalt D, Stefanelli RM, Spinks PE. Différences et similitudes dans l'experience des méres et péres d'un enfant ayant deficience. Les Cahiers Internationaux de Psychologie Sociale 2003; 3(5): 73-82.

3. Pechalt D. Lánnonce de la deficience et processus dádaptation de la famille handicap, medecine, éthique. Les Cahiers de l'Afrée 1994, 6(8): 81-88.

4. Glat R. Questões atuais em educação especial. A integração social dos portadores de deficiência: uma reflexão. Rio de Janeiro(RJ): Sette Letras; 1995.

5. Santos RS. Ser mãe de uma criança especial: do sonho à realidade. [tese de doutorado]. Rio de Janeiro (RJ): Escola de Enfermagem Anna Nery/UFRJ; 1995.

6. Souza MJ, Carvalho V. A família da pessoa Down na ótica da mãe: um estudo para a prática de cuidar. Rio de Janeiro (RJ):UFRJ/EEAN; 2000.

7. Minayo MCS. Pesquisa social: teoria, método e criatividade. $16^{\mathrm{a}}$ ed.Petrópolis (RJ): Vozes; 2000.

8. Brioschi LR, Trigo MHB. Relatos de vida em ciências sociais: considerações metodológicas. Ciência e Cultura 1987; 7 (39): 631-36.

9. Bertaux D. L'Approche biografique: sa valideté méthodologique, ses otenctialialités. Cahiers Internationaux de Sociologie 1980; 69: 197-25.

10. Rodrigues MSP, Leopardi MT. 0 método de análise de conteúdo: uma versão para enfermeiros. Fortaleza (CE): Fundação Cearense de Pesquisa e Cultura; 1999.

11. Haddad MCL. Importância do apoio psicológico aos enfermeiros que assistem pacientes terminais. Rev Enferm Moderna 2004; 3(2):9-16.

12. Kubbler-Ross E. Sobre a morte e o morrer. São Paulo (SP): EDART; 1997.
13. Gauderer EC. Autismo. $3^{\mathrm{a}}$ ed. São Paulo (SP): Atheneu; 1993.

14. Beck CLC. 0 sofrimento do trabalhador - da banalização à resignificação ética na organização da enfermagem. Florianópolis (SC): UFSC; 2001.

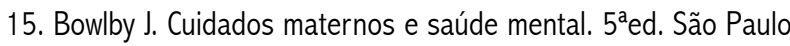
(SP): Martins Fontes; 1996.

16. Dejours C. A loucura do trabalho. $3^{\mathrm{a}}$ ed. São Paulo (SP): Cortez; 1994.

17. Pechalt $D$, Lefèbvre $H$. Intervention précoce auprés de parents ayant une déficience: un lieu d'apprentissages pour les families et les intervenantes. Apprentissage et Socialisation 2004; 1 (7): 105-17.

18. Popim RC. 0 cuidador na ação cuidar na enfermagem oncológica: uma perspectiva orientada sob o enfoque de Alfred Schütz. [tese de doutorado]. Ribeirão Preto (SP): Escola de Enfermagem de Ribeirão Preto/USP; 2001.

\section{Sobre as Autoras}

\section{lêda Maria Ávila Vargas Dias}

Professora Doutora da Faculdade de Enfermagem da Universidade Federal de Juiz de Fora.

\section{Rosangela da Silva Santos}

Professora Doutora em Enfermagem na Escola de Enfermagem Anna Nery/ Universidade Federal do Rio de Janeiro. 